Anaesthesist $2022 \cdot 71$ (Suppl 2):S224-S232 https://doi.org/10.1007/s00101-021-01076-6 Received: 21 April 2021

Revised: 1 November 2021

Accepted: 7 November 2021

Published online: 22 December 2021

(c) The Author(s) 2021

\section{Ultrasound-guided bilateral erector spinae plane block in laparoscopic colon cancer surgery}

\section{A randomized controlled prospective trial}

Qijin $\mathrm{Li}^{1,2} \cdot$ Quanchu $\mathrm{Li}^{1,2} \cdot$ Weiping Peng ${ }^{1,2} \cdot$ Zhenzhen Liu ${ }^{1,2} \cdot$ Yaohai Mai ${ }^{1,2}$. Congying Shi ${ }^{3} \cdot$ Ping $\mathrm{Mo}^{1,2}$

${ }^{1}$ Department of Anesthesiology, Affiliated Nanhai Hospital of Southern Medical University, Foshan, China ${ }^{2}$ Department of Anesthesiology, The Sixth Affiliated Hospital, South China University of Technology, Foshan, China

${ }^{3}$ Department of Experimental Center, Guangzhou Municipality Tianhe Nuoya Bio-engineering Co. Ltd, Guangzhou, China

\title{
Abstract
}

Background: The efficacy of erector spinae plane block (ESPB) for pain control in other surgeries remains an interesting topic of discussion. This study aimed to evaluate the safety and efficacy and quality of recovery of ultrasound-guided bilateral ESPB in laparoscopic surgery for colon cancer.

Material and methods: In this study 50 patients were included and randomly divided into the intervention group ( $\mathrm{E}$ group, $n=25$ ) and the control group (C group, $n=25$ ). Patients in the $E$ group received general anesthesia with preoperative bilateral ultrasound-guided ESPB, whereas patients in the $C$ group received general anesthesia with saline injection in the erector spinae plane preoperatively. Data on intraoperative and postoperative anesthetic effects and the effect on enhanced recovery after surgery were recorded and analyzed.

Results: Rocuronium consumption in the intervention group was $82.80 \pm 21.70 \mathrm{mg}$, which was lower than that in the control group $(P<0.05)$. Visual analog scale scores at 2,6 , and $24 \mathrm{~h}$ after surgery in the intervention group were lower than those in the control group $\left(F_{\text {between }}=34.034, P=0.000\right)$. The time to ambulation, consumption of ketorolac tromethamine, time to oral intake and hospital stay after operation in the intervention group were significantly lower than those in the control group $(P<0.05)$. The block area at the different baselines was significant $\left(F_{\text {between }}=3.211, P=0.009\right)$. The association between baseline and time was significant $\left(F_{\text {baseline }} *\right.$ time $\left.=3.268, P=0.001\right)$. Conclusion: This study confirmed that ultrasound-guided ESPB technology is safe and beneficial for patients with colon cancer undergoing laparoscopic colon surgery.

\section{Keywords}

ESPB · Oncology $\cdot$ ERAS · Rocuronium · Sensory extent

The authors Qijin Li and Quanchu Li contributed equally to the manuscript.

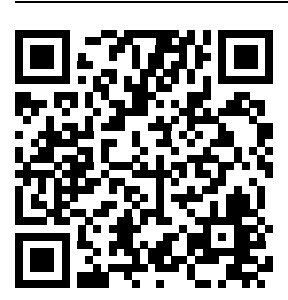

\section{Introduction}

Colorectal cancer is one of the most common tumors worldwide [1, 2]. The American Cancer Society estimated that 95,520 new cases of colon cancer were diagnosed in the United States in 2017 [3]. Both total mesorectal excision and complete meso- colic excision have become the standard techniques in colon cancer surgery to reduce local recurrence and mortality [4].

Improved standards in perioperative care can be attributed to a wide range of changes in clinical interventions. Enhanced recovery after surgery (ERAS) has been one of the most significant recent 
breakthroughs [5], particularly in patients undergoing abdominal surgery. The ERAS protocol is a multimodal, multidisciplinary, and evidence-based approach that reduces surgical stress, enhances early recovery after surgery, and improves patient outcomes [6]. Most ERAS protocols consist of perioperative, intraoperative, and postoperative care. Thus, the responsibility of the anesthetist is to modify the management to increase both the quality and outcome of perioperative care [7]. Regional anesthesia complements and enhances multimodal analgesia for abdominal surgery and improves surgical outcomes [8-11].

Thoracic epidural analgesia (TEA) and transversus abdominis plane (TAP) blocks are common interventions used in major open abdominal surgery but have certain disadvantages [12-15]. The ultrasoundguided erector spinae plane block (ESPB) was first described by Forero et al. [16] in 2016 for chronic and postoperative thoracic pain. Compared to TAP block, ESPB has the advantages of TEA as it has been reported to provide a wide range of sensory blockade in the abdomen [17-20] and thorax [21-25]. The ESPB also has a lower risk of complications than TEA or paravertebral blocks $[16,26,27]$.

To evaluate the perioperative analgesic efficacy and the quality of recovery of ESPB in patients undergoing laparoscopic surgery for colon cancer, we conducted a randomized double-blind trial for laparoscopic colon cancer surgery to verify the safety and efficacy of ESPB. Its ERAS efficacy was also evaluated. This study quantified and assessed the block area in vivo using the temperature and prick test, after setting baselines for testing by assigning bones from $\mathrm{T} 1$ to $\mathrm{L} 5$.

\section{Abbreviations}

\begin{tabular}{ll} 
BIS & Bispectral index \\
CME & Complete mesocolic excision \\
ERAS & Enhanced recovery after surgery \\
ESP & Erector spinae plane \\
ESPB & Erector spine plane block \\
TAP & Transversus abdominis plane \\
$T E A$ & Thoracic epidural analgesia \\
$T M E$ & Total mesorectal excision \\
$V A S$ & Visual analog scale \\
\hline
\end{tabular}

\section{Methods}

\section{Aim, design and participants}

All procedures followed were in accordance with the ethical standards of the responsible committee on human experimentation and with the Declaration of Helsinki of 2000. Informed consent was obtained from all patients included in the study. The study was approved by the ethics committee of the Nanhai Hospital Affiliated to Southern Medical University (NO.: (2019) 531). This prospective randomized controlled double-blind study was registered in the Chinese Clinical Trial Registry (trial ID: ChiCTR2000031255, 26.03.2020). The study adhered to the Consolidated Standards of Reporting Trials (CONSORT) guidelines.

The inclusion criteria were as follows: (1) patients aged 18-75 years, (2) American Society of Anesthesiologists (ASA) physical status I-II, (3) New York Heart Association class I-II, (4) all patients scheduled for laparoscopic surgery for colon cancer, and (5) patient or family member who provided written informed consent. The exclusion criteria were as follows: (1) patients with abnormal coagulation function; (2) patients with severe heart and lung disease and liver and kidney dysfunction, (3) patients allergic to local anesthetic drugs or opioids, (4) patients receiving preoperative chemoradiotherapy, (5) patients unable to cooperate or communicate, (6) patients with chronic pain or a long history of mental illness, (7) patients with serious complications that were not caused by anesthesia that resulted in a prolonged hospital stay, (8) patients with any contraindications to regional anesthesia, and (9) patients who proactively withdrew from the study.

To evaluate the safety and efficacy and quality of recovery of ultrasound-guided bilateral ESPB in laparoscopic surgery for colon cancer, patients were assigned into two groups: the ESPB (E group) and control groups (C group). Patients in the $\mathrm{E}$ group received general anesthesia with preoperative bilateral ultrasound-guided ESPB. Patients in the $C$ group received general anesthesia with preoperative bilateral ultrasound-guided erector spinae plane (ESP) saline injection.

\section{Interventions}

Ultrasound-guided ESPB was performed under strict aseptic precautions. Each patient was placed in the right lateral decubitus position and underwent routine monitoring including electrocardiography; blood pressure, and pulse oximetry; and peripheral venous access. Invasive arterial blood pressure monitoring, central venous catheter placement right jugular internal vein, and catheterization in the right neck were performed. All the anesthesia operations were performed by the same experienced, skilled and senior attending physician. The T7 spinous process was located by direct palpation of the spinous processes starting from the $\mathrm{C} 7$ downward. The tip of the T7 transverse process was then identified using a linear array high-frequency ultrasound probe placed in a transverse orientation. By rotating the ultrasound probe to a portrait orientation, a parasagittal view of the skin, subcutaneous tissue, trapezius, and erector spinae muscle was displayed. The T7 transverse process could be confirmed when the rhomboid muscle disappeared because the rhomboid muscle was located at the T5-T6 vertebral level. To confirm correct needle insertion, the needle was inserted in-plane craniocaudally until it reached the $\mathrm{T7}$ transverse process and $0.5-1.0 \mathrm{~mL}$ saline was injected. After the injection the distribution of the injected saline was assessed in order to verify the correct needle position and injection plane. No distension observed in the erector spinae muscle meant that the tip of the needle was in the correct plane. Then, patients in the E group were injected with $20 \mathrm{~mL}$ of ropivacaine $(0.25 \%)$ into the ESP bilaterally. Patients in the $\mathrm{C}$ group were injected with $20 \mathrm{~mL}$ of saline bilaterally. All the injections were performed in the correct plane. Both groups received general intravenous anesthesia by subsequently injecting $0.4 \mu \mathrm{g} / \mathrm{kg}$ sufentanil, $2 \mathrm{mg} / \mathrm{kg}$ propofol, and $0.6 \mathrm{mg} / \mathrm{kg}$ rocuronium. Tracheal intubation was performed after muscle relaxation. Mechanical ventilation was then performed and the tidal volume was set to $6-8 \mathrm{~mL} / \mathrm{kg}$ and respiratory rate to $12-16$ times/min. Moreover, end-tidal carbon dioxide was maintained at $35-45 \mathrm{~mm} \mathrm{Hg}$. A bispectral index (BIS) 


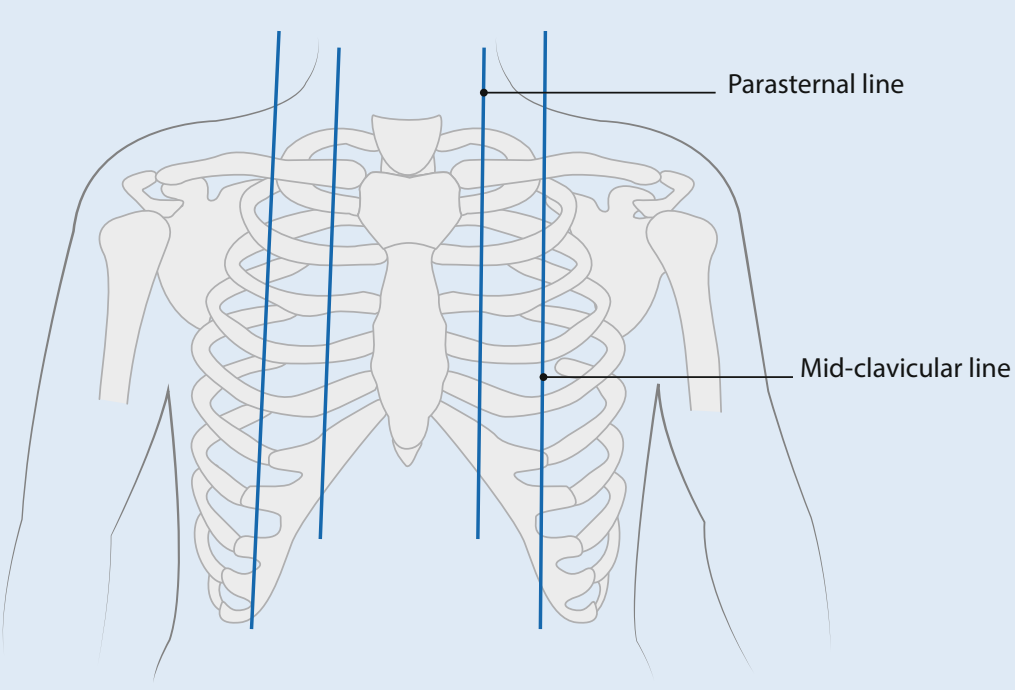

Front

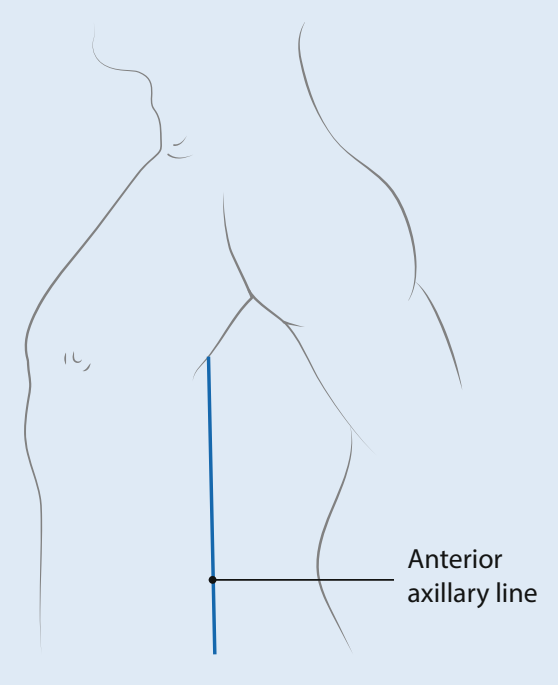

Profile

Fig. $1 \Delta$ Baselines of the temperature and prick test

monitor was used to monitor anesthesia depth, BIS values were controlled to 46-60 and mean arterial blood pressure was maintained at $70-100 \mathrm{~mm} \mathrm{Hg}$. A dual channel target-controlled infusion pump (WeiLiFangZhou TCI-III-B [Nan Ning, Guang Xi, China]) was used to infuse propofol, remifentanil and rocuronium for maintaining anesthesia during surgery. The propofol was infused $1-4 \mu \mathrm{g} / \mathrm{mL}$ in the Marsh mode and remifentanil was infused $2-4 \mathrm{ng} / \mathrm{mL}$ in target-controlled infusion with effect-site concentration. The dosage of rocuronium can be adjusted according to the surgeon's need for muscle relaxation during surgery. An electronic intravenous analgesia pump was used in both groups postoperatively. Sufentanil $(2 \mu \mathrm{g} / \mathrm{kg}$ ) and tropisetron $(4 \mathrm{mg})$ were diluted in $100 \mathrm{~mL}$ of saline for the analgesia pump. The pump infusion rate was $2 \mathrm{~mL} / \mathrm{h}$, with a single patientcontrolled intravenous analgesia dose of $0.5 \mathrm{~mL}$ and duration of $15 \mathrm{~min}$. Ketorolac tromethamine ( $30 \mathrm{mg}$ per dose) was administered as an analgesic remedy when pain became unbearable (visual analog scale $[\mathrm{VAS}]>5$ ).

The temperature and prick test were used separately to detect the temperature by alcohol evaporation and pain sensory extent of the block after surgery. The left parasternal line, left mid-clavicular line, left anterior axillary line, right parasternal line, right mid-clavicular line, and right anterior axillary line were used as baselines (- Fig. 1).

\section{Outcome measures}

Postoperative pain was assessed using the VAS at 2, 6, 24, and $48 \mathrm{~h}$ postoperatively. A rescue analgesic was infused when the patient had a VAS score $>5$, and the total analgesic consumption of ketorolac tromethamine was recorded within $48 \mathrm{~h}$. Arterial blood was collected upon admission to the operating room (Time 1), $10 \mathrm{~min}$ after extubation (Time 2), and $24 \mathrm{~h}$ after operation (Time 3), and stress response indices such as blood glucose and lactate were then detected. Components of ERAS, such as the first time of anal exhaust, the time of leaving the bed, eating, bladder catheter removal, and hospital stay, were recorded. Data regarding the infusion of sufentanil and remifentanil during surgery were recorded. The numbers of pressing in the analgesia pump within $48 \mathrm{~h}$ postoperatively were recorded, as were the postoperative complications such as bradycardia, hypotension, nausea, vomiting, pruritus, respiratory depression or vertigo. The sensory extent of the block was noted at 6,12 , and $24 \mathrm{~h}$ postoperatively. The L5-T1 bones were assigned as variables 1-17 according to the order of the lumbar vertebrae to the thoracic vertebrae from bottom to top.

\section{Statistical analyses}

All surgeons, nurses, follow-up data collection doctor, statisticians, and patients were blinded to group allocation. Only the anesthesiologists performing the blocks and operating room nurses were not blinded. The surgeons who performed the colon cancer surgery were blinded to the group allocation. None of the anesthesiologists involved in the study followed up the patient in the postoperative period and collected data for the study. The follow-up data were collected when patients were hospitalized by a designated doctor. Ward nurses in the postoperative period were blinded to the group allocation. Qijin Li, Quanchu Li, Weiping Peng, Zhenzhen Liu, and Yaohai Mai enrolled participants. Participants were assigned to groups $E$ and $C$ through random sampling method by Doctor Ping Mo. The $E$ and $C$ groups were assigned as " $\mathrm{A}$ " and "B" by Doctor Ping Mo. The statistician was blinded when analyzing. The groups were blinded until all data collection was complete.

A previous trial found that the mean \pm standard deviation of VAS pain score at $24 \mathrm{~h}$ postoperatively in patients with ESPB was $2.76 \pm 0.68$. We hypothesized a common within-group standard deviation of 0.7 and 


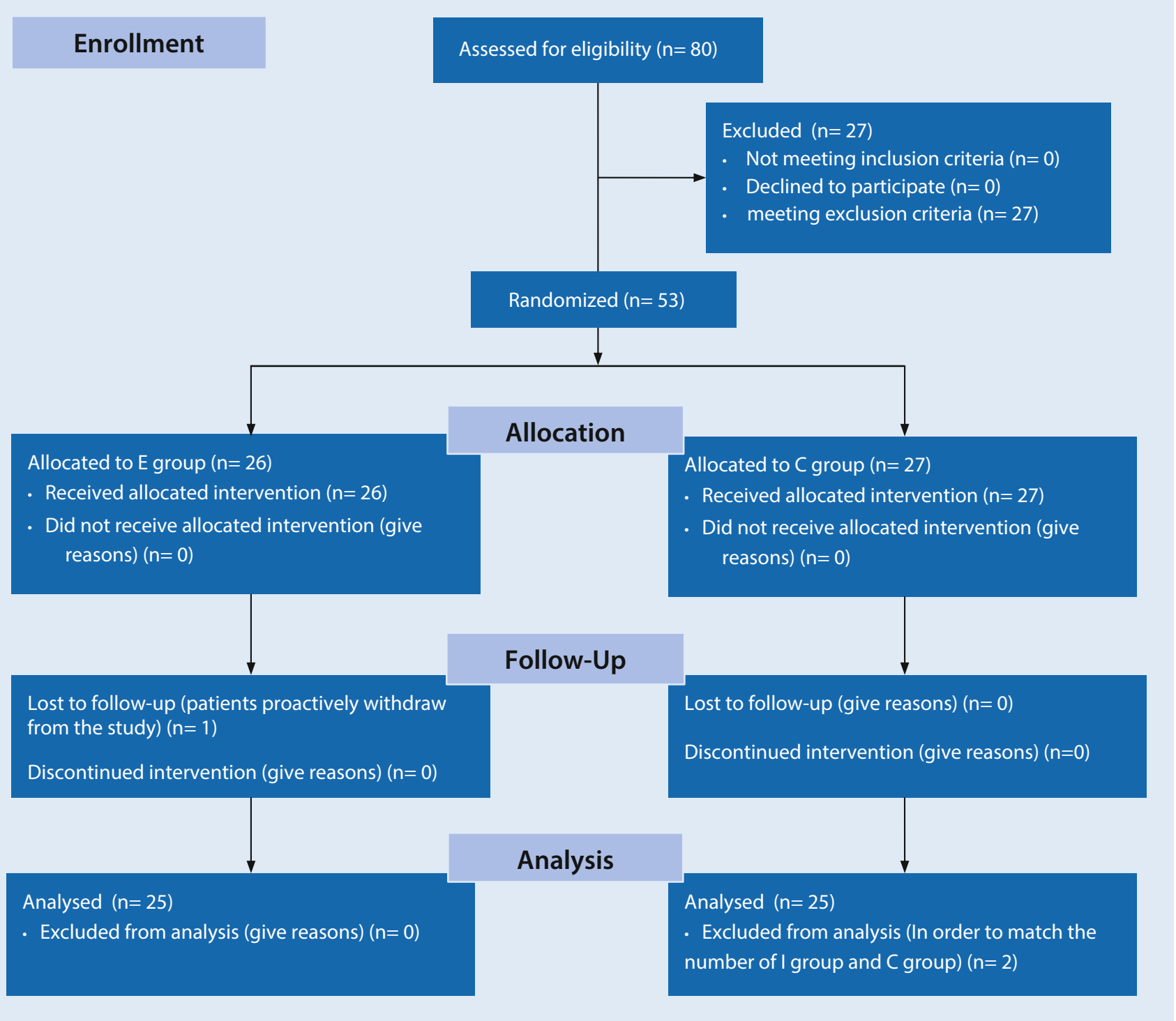

Fig. $2 \triangle$ CONSORT flow diagram

calculated that a sample size of 25 patients per group (total 50) would provide $80 \%$ power at a two-sided a value of 0.05 to detect the difference in VAS pain score at $24 \mathrm{~h}$ postoperatively between patients in the $E$ and $C$ groups. To account for possible protocol violations, we enrolled a total of 80 participants.

Descriptive analysis was used to analyze the characteristics of the selected patients. Baseline clinical characteristics of the two groups were compared using the $X^{2}$-test. Mean values and standard deviation were calculated and determined using a t-test for each quantitative variable. Repeated measures analysis of variance (ANOVA) was performed to compare repeated measures variables. The variable model area was calculated, and repeated measures ANOVA was used to evaluate anesthesia efficacy. Statistical significance was set at $P<0.05$. All data were analyzed using the PASW Statistics for Windows version 18.0 statistical software (Chicago: SPSS Inc., 2009).

\section{Results}

\section{Patient characteristics}

The study recruited and followed up participants from 1 July 2019, to 31 August 2020. During the study period, 80 patients were considered eligible; however, 27 patients were excluded for meeting the exclusion criteria. A total of 53 patients were finally included and were randomized and 27 patients received general anesthesia with preoperative saline injection (C group), whereas the other 26 patients received ESPB in addition to general anesthesia ( $E$ group). One patient from the E group withdrew from the study during the follow-up period. To match the number of the $E$ group and the $C$ group, two patients in the $C$ group were randomly excluded. The CONSORT flow diagram is shown in 0 Fig. 2 . There was no significant difference between the demographics of patients in the control group and the intervention group (•Table 1). 
Table 1 Comparison of patient demographic data

\begin{tabular}{|l|l|l|l|}
\hline & E group $(n=25)$ & C group $(n=25)$ & $P$ \\
\hline Sex (male:female) & $15: 10$ & $15: 10$ & 1.000 \\
\hline Age (years) & $62.48 \pm 10.96$ & $67.89 \pm 10.89$ & 0.087 \\
\hline Body mass index $\left(\mathrm{kg} / \mathrm{m}^{2}\right)$ & $21.28 \pm 2.96$ & $20.35 \pm 3.51$ & 0.333 \\
\hline
\end{tabular}

\begin{tabular}{|l|l|l|l|}
\hline Table 2 Comparison of anesthetic dosage during surgery \\
\hline & E group $(n=25)$ & C group $(n=25)$ & $P$ \\
\hline Propofol $(\mathrm{mg})$ & $1056.00 \pm 445.35$ & $1028.80 \pm 473.68$ & 0.835 \\
\hline Remifentanil $(\mu \mathrm{g})$ & $1209.20 \pm 364.36$ & $1082.76 \pm 420.70$ & 0.262 \\
\hline Rocuronium $(\mathrm{mg})$ & $82.80 \pm 21.70$ & $116.60 \pm 48.38$ & 0.003 \\
\hline
\end{tabular}

Table 3 Comparison of blood glucose and lactate at different detection times, postoperative VAS score, and ERAS efficacy

\begin{tabular}{|c|c|c|c|c|c|c|}
\hline & $\begin{array}{l}\text { E group } \\
(n=25)\end{array}$ & $\begin{array}{l}\text { C group } \\
(n=25)\end{array}$ & $F_{\text {within }}$ & Fbetween & $F_{\text {group * }}$ time & $P$ \\
\hline \multicolumn{7}{|c|}{ Blood glucose ( $\mathrm{mmol} / \mathrm{L})$} \\
\hline $\mathrm{T} 1$ & $6.53 \pm 2.53$ & $6.60 \pm 1.54$ & \multirow[t]{3}{*}{$6.953^{* *}$} & \multirow[t]{3}{*}{0.047} & \multirow[t]{3}{*}{0.151} & - \\
\hline $\mathrm{T} 2$ & $7.33 \pm 1.96$ & $7.59 \pm 1.74$ & & & & - \\
\hline T3 & $7.19 \pm 2.82$ & $7.20 \pm 1.48$ & & & & - \\
\hline \multicolumn{7}{|c|}{ Blood lactate $(\mathrm{mmol} / \mathrm{L})$} \\
\hline $\mathrm{T} 1$ & $1.00 \pm 0.59$ & $0.65 \pm 0.40$ & \multirow[t]{3}{*}{$29.770^{* *}$} & \multirow[t]{3}{*}{3.175} & \multirow[t]{3}{*}{0.362} & - \\
\hline $\mathrm{T} 2$ & $1.41 \pm 0.71$ & $1.14 \pm 0.63$ & & & & - \\
\hline T3 & $1.36 \pm 0.84$ & $1.12 \pm 0.45$ & & & & - \\
\hline \multicolumn{7}{|l|}{ VAS score } \\
\hline $2 \mathrm{~h}$ after surgery & $2.12 \pm 0.53$ & $2.32 \pm 0.75$ & \multirow[t]{3}{*}{$32.801^{* *}$} & \multirow[t]{3}{*}{$10.634^{* *}$} & \multirow[t]{3}{*}{$7.021^{* *}$} & - \\
\hline $6 \mathrm{~h}$ after surgery & $2.72 \pm 0.61$ & $3.68 \pm 0.63$ & & & & - \\
\hline $24 \mathrm{~h}$ after surgery & $2.76 \pm 0.83$ & $3.32 \pm 0.75$ & & & & - \\
\hline $\begin{array}{l}\text { Time to ambula- } \\
\text { tion (h) }\end{array}$ & $30.40 \pm 10.20$ & $51.04 \pm 14.39$ & - & - & - & 0.000 \\
\hline $\begin{array}{l}\text { Analgesia reme- } \\
\text { diation consump- } \\
\text { tion of ketorolac } \\
\text { tromethamine } \\
\text { (mg) }\end{array}$ & $24.00 \pm 35.71$ & $51.60 \pm 43.75$ & - & - & - & 0.018 \\
\hline $\begin{array}{l}\text { Anal exhaust time } \\
\text { (h) }\end{array}$ & $53.44 \pm 18.29$ & $60.64 \pm 16.19$ & - & - & - & 0.147 \\
\hline $\begin{array}{l}\text { Time of bladder } \\
\text { catheter removal } \\
\text { (h) }\end{array}$ & $72.00 \pm 142.32$ & $54.08 \pm 33.94$ & - & - & - & 0.543 \\
\hline $\begin{array}{l}\text { Time to oral in- } \\
\text { take (h) }\end{array}$ & $36.96 \pm 17.97$ & $52.00 \pm 16.45$ & - & - & - & 0.003 \\
\hline $\begin{array}{l}\text { Hospital stay after } \\
\text { operation (days) }\end{array}$ & $10.08 \pm 5.05$ & $12.52 \pm 2.60$ & - & - & - & 0.037 \\
\hline \multicolumn{7}{|l|}{${ }^{*} P<0.05,{ }^{* *} P<0.01$} \\
\hline
\end{tabular}

\section{Outcomes}

The consumption of rocuronium in the E group was $82.80 \pm 21.70 \mathrm{mg}$, which was significantly lower than that in the $C$ group $(P<0.05)$; however, there was neither a statistically significant difference between the dosages of remifentanil and propofol (סTable 2) nor in the amount of lactic acid in the blood between the two groups ( $F_{\text {between, }} P>0.05$ ). The associations between lactate and glucose in the blood over time were not significant in the two groups ( $F_{\text {group }}{ }^{*}$ timer $P>0.05$ ) (- Table 3).

The VAS scores at 2, 6, and $24 \mathrm{~h}$ after surgery in the $E$ group were lower than those in group $C\left(F_{\text {between }}=34.034\right.$,
$P=0.000)$. Furthermore, the association between anesthesia methods and VAS time was statistically significant between the two groups $\left(F_{\text {group }} *\right.$ time $=9.759$, $P=0.000$ ) (• Table 3), indicating that ESPB anesthesia method had a longer analgesic effect. For ERAS, the time of leaving the bed, analgesia remediation consumption of ketorolac tromethamine, meal time after surgery and hospital stay in the $E$ group were significantly lower than those in the $C$ group $(P<0.05)$. Differences in parameters such as anal exhaust time and time of bladder catheter removal between groups were not statistically significant $(P>0.05)$ (- Table 3).

The incidences of postoperative complications are shown in $\mathbf{\bullet}$ Table 4 . The incidences of postoperative complications in $\mathrm{E}$ group were lower than that in $\mathrm{C}$ group, but not significant different $(P>0.05)$.

\section{Sensory extent of the block}

The extent of the sensory block was determined by the temperature and prick test for the E group (- Fig. 3a). Over time, the extent of the block gradually decreased $\quad\left(F_{\text {within }}=154.128, P=0.000\right)$. The difference in the blocked areas using the different baselines was significant $\left(F_{\text {between }}=3.211, P=0.009\right)$. The association between baseline and time was significant $\left(F_{\text {baseline }} *\right.$ time $\left.=3.268, P=0.001\right)$, indicating that the extent of the sensory block diminished over time (- Table 5; - Fig. 3b-d).

\section{Discussion}

As a new blocking technique, the use of erector spinal plane block has been reported in mammary glands, thoracoscopic and spinal surgery [28]. ESPB is a promising regional anesthesia technique. Physicians can reach proficiency in performing these blocks in a shorter time than other more invasive techniques such as paravertebral blocks; however, there are only a few randomized controlled double-blind studies on abdominal surgery.

Our results showed that the consumption of rocuronium in E group was significantly lower than that of $C$ group. We reviewed all the surgical records in this study and found that 5 patients in the con- 
Table 4 Comparison of postoperative complications

\begin{tabular}{|l|l|l|l|l|l|l|l|}
\hline & \multicolumn{2}{l}{ Postoperative complications $n(\%)$} \\
\cline { 2 - 8 } & Bradycardia & Hypotension & Nausea and vomiting & Vertigo & Pruritus & Respiratory depression & Total \\
\hline E group $(n=25)$ & $0(0)$ & $0(0)$ & $1(4)$ & $0(0)$ & $0(0)$ & $0(0)$ & $1(4)$ \\
\hline C group $(n=25)$ & $0(0)$ & $0(0)$ & $2(8)$ & $1(4)$ & $0(0)$ & $0(0)$ & $3(12)$ \\
\hline$X^{2}$ & - & - & - & - & - & - & 1.087 \\
\hline$P$ & - & - & - & - & - & - & 0.297 \\
\hline
\end{tabular}

\begin{tabular}{|l|l|l|l|}
\hline Table $\mathbf{5}$ Repeated measures ANOVA of block area \\
\hline & $\mathbf{6} \mathbf{h}$ after surgery & $\mathbf{1 2} \mathbf{h}$ after surgery & $\mathbf{2 4} \mathbf{h}$ after surgery \\
\hline Left parasternal line & $9.92 \pm 1.89$ & $8.96 \pm 1.95$ & $7.52 \pm 2.57$ \\
\hline Left mid-clavicular line & $8.68 \pm 2.56$ & $8.20 \pm 2.48$ & $7.36 \pm 2.60$ \\
\hline Left anterior axillary line & $8.80 \pm 2.61$ & $8.08 \pm 2.68$ & $7.48 \pm 2.47$ \\
\hline Right parasternal line & $11.00 \pm 1.63$ & $9.72 \pm 1.67$ & $8.68 \pm 1.95$ \\
\hline Right mid-clavicular line & $8.92 \pm 1.96$ & $8.32 \pm 1.91$ & $7.36 \pm 1.82$ \\
\hline Right anterior axillary line & $8.32 \pm 1.63$ & $7.80 \pm 1.98$ & $7.28 \pm 1.70$ \\
\hline$F_{\text {within }}$ & $154.128^{* *}$ & \\
\hline$F_{\text {between }}$ & $3.211^{* *}$ & \\
\hline$F_{\text {baseline }}^{*}$ time & $3.268^{* *}$ & \\
\hline${ }^{*} P<0.05,{ }^{*} P<0.01$ & \multicolumn{5}{|l}{} \\
\hline
\end{tabular}

trol group received an additional dosage of $0.3 \mathrm{mg} / \mathrm{kg}$ rocuronium due to intraoperative body movements or dissatisfaction with the effect of muscle relaxation but no such situation occurred in the experimental group. We speculate that is the main reason why the rocuronium consumption between two group is significant different, and ESPB could provide a better muscle relaxation. The consumption of propofol and remifentanil during operation between two groups were not significantly different. This could be attributed to TCI target-controlled remifentanil under the guidance of ERAS, which lead to a relatively stable circulation and no drastic hemodynamic fluctuation. Glucose and lactate levels in the blood were not significantly different between the two groups at different times, indicating that ESPB has no evident inhibitory effect on the stress injury induced by surgery. The same remifentanil consumption in both groups indicated that the ESP block did not produce visceral analgesia but both groups were given analgesic pump after operation, which had a certain effect on visceral pain. The bilateral ultrasound-guided ESPB resulted in a significant postoperative reduction of pain through the VAS scores at 2,6 , and $24 \mathrm{~h}$. The difference in VAS may be due to the pain of the wound, and ESPB can provide better analgesia. The numbers of nausea, vomiting and vertigo in the $\mathrm{C}$ group were higher than in $\mathrm{E}$ group. It was possible that the number of postoperative salvage analgesia and analgesia pump compressions in the $\mathrm{C}$ group were more than that in the E group, resulting in increased adverse reactions. This may also indicate that the analgesic effect of ESP in E group was better than $C$ group. We had also assessed the VAS scores of patients in two groups at $48 \mathrm{~h}$. The VAS score of the E group at $48 \mathrm{~h}$ was $2.40 \pm 0.76$ and that of the $C$ group was $2.32 \pm 0.56$. The VAS score data of $48 \mathrm{~h}$ were both low without significant difference; thus, we did not analyze it in the results. The time to ambulation, analgesia remediation consumption of ketorolac tromethamine, time to oral intake and hospital stay after operation in the E group were significantly reduced, indicating that the effects of ESPB on ERAS were better than the $C$ group. The concept of ERAS is popular in gastrointestinal surgery. The ESPB anesthesia can effectively reduce postoperative pain and postoperative complications in patients, meeting the technical requirements of ERAS. The results of our investigations in the extent of sensory block showed that the ranges of anesthesia within $24 \mathrm{~h}$ in different baselines were both between $\mathrm{T} 12$ and T5. The left and right parasternal anesthesia lines were more extensive than others, but the effect of anesthesia declined more rapidly. The anesthetic effect in the right side of the body was stronger than the left side, which may be related to the lateral position during performance of the ESPB; however, the range of anesthesia for $24 \mathrm{~h}$ was between $\mathrm{T} 12$ and T5. The declines in the sensory extent of the block at $12 \mathrm{~h}$ and $24 \mathrm{~h}$ were $8.67 \%$ and $18.2 \%$, respectively. In addition, No ESPB-related complications occurred (hematoma etc.), no ESPB failed due to technical difficulties, proving that ESPB under ultrasound guidance is safe and effective. Although the history of ESPB is short, and few controlled clinical trials have been published, there is an abundance of case reports. Some dealt with analgesia for abdominal surgery $[19,29,30]$, but not for laparoscopic surgery for colon cancer and quality of recovery. Our prospective randomized controlled trial has confirmed that ultrasound-guided ESPB technology is safe and beneficial for laparoscopic colon surgery for colorectal cancer.

In this study, we found that the standard deviation of the block area was large, suggesting that the block area of ESPB may be significantly different among individuals. ESPB was placed at T7 in this study and the block spread to $\mathrm{T} 1$, in contrast to another study [31]. Cadaver studies examining local anesthetic spread postESPB have shown inconsistent dye spread [32], whereas our data showed that the block area at different baselines did not significantly differ.

Our study has some limitations. First, this was a single-center study. The number of participants enrolled was small, so the applicability of results may be limited. Second, there was no effective evaluation indexused in this study to distinguish visceral pain from incisional pain, which needs to be confirmed by further studies. Third, the mechanism of ESPB should be further studied by exploring the diffusion pathway 

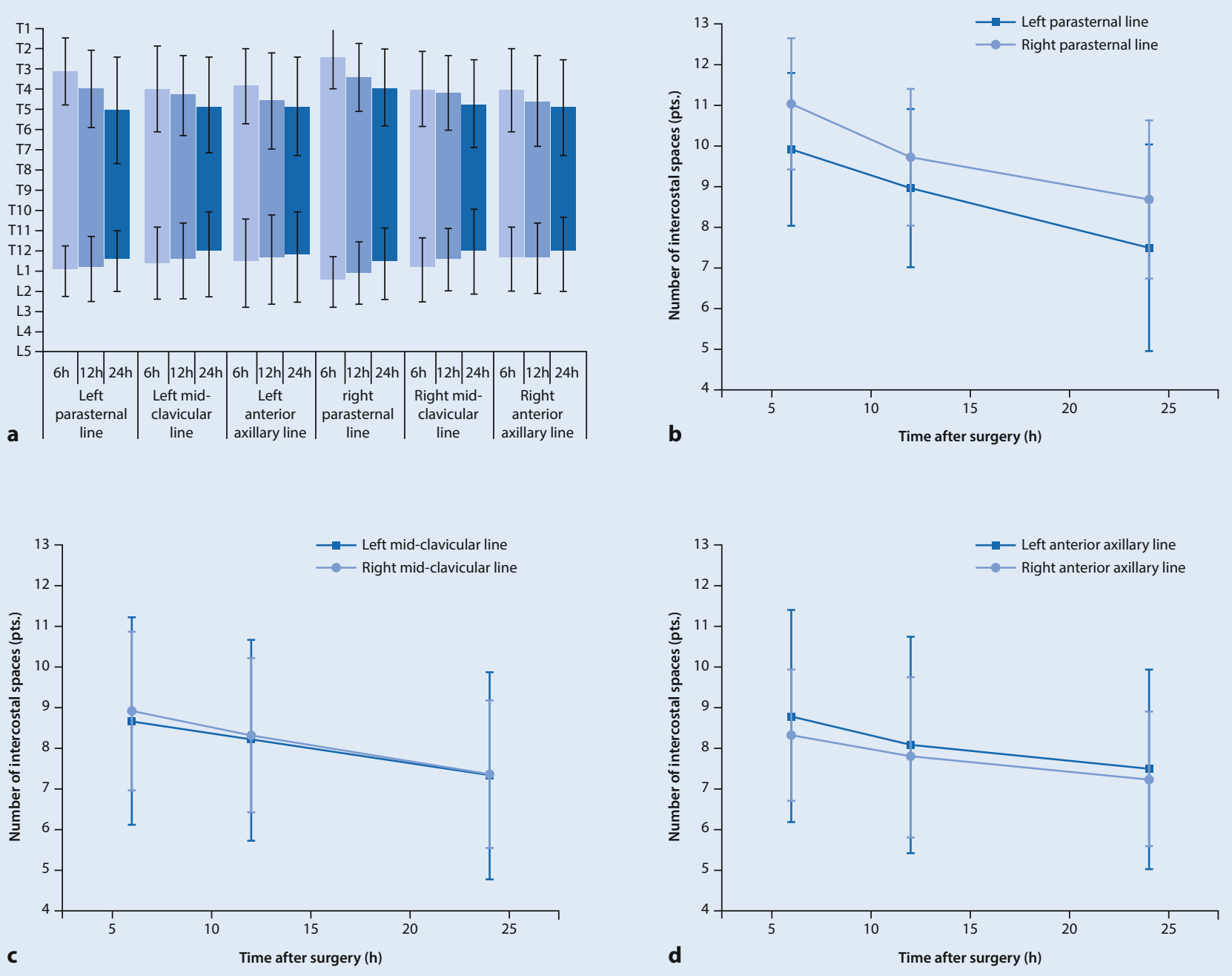

Fig. $3 \Delta$ Sensory extent of the erector spine muscle block after surgery. a The extent of the sensory block shown by the vertebral column; $\mathbf{b}$ The block extent of parasternal line is shown in number of intercostal spaces; $\mathbf{c}$ The block extent of mid-clavicular line is shown in number of intercostal spaces; $\mathbf{d}$ The block extent of anterior axillary line is shown in number of intercostal spaces

after drug injection by adding a contrast agent to local anesthetics. Fourth, our study found that some patients still have pain after surgery $>24 \mathrm{~h}$. Dexamethasone or dexmedetomidine can be added to the anesthetics to prolong block time in further studies. Finally, the recovery quality scale, 15 -item quality of recovery and other relevant evaluation indicators can be used to evaluate the quality of the patient recovery and postoperative status.

In conclusion, our prospective randomized controlled trial has confirmed that ultrasound-guided ESPB technology is safe and beneficial and improves recovery rate and ERAS in patients with colon cancer undergoing laparoscopic colon surgery.

\section{Corresponding address}

\section{Ping Mo, MD}

Department of Anesthesiology, Affiliated Nanhai Hospital of Southern Medical University 40 Foping Road, 528200 Foshan, Guangdong, China

pop_pan@126.com

Acknowledgements. The authors would like to thank all patients who participated in this study. We would also like to thank Editage (www.editage.cn) for English language editing.

Author Contribution. Qijin Li, Quanchu Li contributions to the conception, design of the work, the acquisition, analysis, interpretation of data, drafted the work and revised it. Weiping Peng, Zhenzhen Liu, Yaohai Mai and Congying Shi contributions to the acquisition, analysis, interpretation of data. Ping Mo contributions to the conception, design of the work and revised the manuscript. All authors read and approved the final manuscript and agreed both to be personally accountable for the author's own contributions and ensured that questions related to the accuracy or integrity of any part of the work.

\section{Declarations}

Conflict of interest. Q. Li, Q. Li, W. Peng, Z. Liu, Y.Mai, C. Shi and P. Mo declare that they have no competing interests.

Ethical standards. All procedures followed were in accordance with the ethical standards of the responsible committee on human experimentation and with the Declaration of Helsinki of 2000. Informed consent was obtained from all patients included in the study. The study was approved by the ethics committee of 
the Nanhai Hospital Affiliated to Southern Medical University (NO.: (2019) 531). All studies performed were in accordance with the ethical standards indicated in each case.

Open Access. This article is licensed under a Creative Commons Attribution 4.0 International License, which permits use, sharing, adaptation, distribution and reproduction in any medium or format, as long as you give appropriate credit to the original author(s) and the source, provide a link to the Creative Commons licence, and indicate if changes were made. The images or other third party material in this article are included in the article's Creative Commons licence, unless indicated otherwise in a credit line to the material. If material is not included in the article's Creative Commons licence and your intended use is not permitted by statutory regulation or exceeds the permitted use, you will need to obtain permission directly from the copyright holder. To view a copy of this licence, visit http://creativecommons.org/licenses/by/4.0/.

\section{References}

1. Ferlay J, Steliarova-Foucher E, Lortet-Tieulent J et al (2013) Cancer incidence and mortality patterns in Europe: estimates for 40 countries in 2012. Eur J Cancer 49(6):1374-1403

2. Fakih MG (2015) Metastatic colorectal cancer: current state and future directions. J Clin Oncol 33(16):1809-1824

3. Hawkins AT, Ford MM, Benjamin Hopkins M et al (2018) Barriers to laparoscopic colon resection for cancer: a national analysis. Surg Endosc 32(2):1035-1042

4. Hohenberger W, Weber K, Matzel K, Papadopoulos T, Merkel S (2009) Standardized surgery for colonic cancer: complete mesocolic excision and central ligation-technical notes and outcome. Colorectal Dis 11(4):354-364 (discussion 364-365)

5. Kehlet H, Dahl JB (2003) Anaesthesia, surgery, and challenges in postoperative recovery. Lancet 362(9399):1921-1928

6. GreerNL, GunnarWP,Dahm Petal (2018) Enhanced recovery protocols for adults undergoing colorectal surgery: a systematic review and meta-analysis. Dis Colon Rectum 61(9):1108-1118

7. El-Boghdadly K, Pawa A (2017) The erector spinae plane block: plane and simple. Anaesthesia 72(4):434-438

8. Power I, McCormack JG, Myles PS (2010) Regional anaesthesia and pain management. Anaesthesia 65(1):38-47

9. Reddi D (2016) Preventing chronic postoperative pain. Anaesthesia 71(1):64-71

10. Xu YJ, Li SY, Cheng Q et al (2016) Effects of anaesthesia on proliferation, invasion and apoptosis of LoVo colon cancer cells in vitro. Anaesthesia 71(2):147-154

11. Ciechanowicz SJ, Ma D (2016) Anaesthesia for oncological surgery - can it really influence cancer recurrence? Anaesthesia 71(2):127-131

12. Guay J, Nishimori M, Kopp S (2016) Epidural local anaesthetics versus opioid-based analgesic regimens for postoperative gastrointestinal paralysis, vomiting and pain after abdominal surgery. Cochrane Database Syst Rev 7:CD1893

13. Chilvers CR, Nguyen MH, Robertson IK (2007) Changing from epidural to multimodal analgesia for colorectal laparotomy: an audit. Anaesth Intensive Care 35(2):230-238

Ultraschallgesteuerter beidseitiger Erector-spinae-plane-Block in der laparoskopischen Kolonkarzinomchirurgie. Eine randomisierte, kontrollierte, prospektive Studie

Hintergrund: Die Wirksamkeit des Erector-Spinae-Blocks (ESPB) zur Schmerzbekämpfung bei anderen Operationen bleibt ein interessantes Diskussionsthema. Diese Studie zielte darauf ab, die Sicherheit und Wirksamkeit sowie die Qualität der Genesung beim ultraschallgesteuerten bilateralen ESPB in der laparoskopischen Chirurgie bei Darmkrebs zu bewerten.

Materialien und Methoden: In diese Studie wurden 50 Patienten eingeschlossen und nach dem Zufallsprinzip in die Interventionsgruppe (E-Gruppe, $n=25$ ) und die Kontrollgruppe (C-Gruppe, $n=25$ ) eingeteilt. Patienten in der E-Gruppe erhielten eine Vollnarkose mit präoperativem bilateralem ultraschallgesteuertem ESPB, während Patienten in der C-Gruppe präoperativ eine Vollnarkose mit Kochsalzinjektion in die Erector-Spinae-Ebene erhielten. Daten zu intraoperativen und postoperativen anästhetischen Effekten und der Wirkung auf eine verbesserte Genesung nach der Operation wurden aufgezeichnet und analysiert.

Ergebnisse: Der Rocuroniumverbrauch in der Interventionsgruppe betrug $82,80 \pm 21,70 \mathrm{mg}$, was niedriger war als in der Kontrollgruppe $(p<0,05)$. Visuelle Analogskalenwerte 2, 6 und $24 \mathrm{~h}$ nach der Operation in der Interventionsgruppe waren niedriger als in der Kontrollgruppe $\left(F_{\text {between }}=34,034, P=0,000\right)$. Die Zeit bis zur Ambration, der Konsum von Ketorolac-Tromethamin, die Zeit bis zur oralen Einnahme und der Krankenhausaufenthalt nach der Operation in der Interventionsgruppe waren signifikant niedriger als in der Kontrollgruppe $(p<0,05)$. Die Blockfläche an den verschiedenen Basislinien war signifikant $\left(F_{\text {between }}=3,211, p=0,009\right)$. Die Assoziation zwischen Baseline und Zeit war signifikant $\left(F_{\text {baseline }}{ }^{*}\right.$ time $\left.=3,268, p=0,001\right)$. Schlussfolgerung: Diese Studie bestätigte, dass die ultraschallgesteuerte ESPB Technologie für Patienten mit Darmkrebs, die sich einer laparoskopischen Dickdarmoperation unterziehen, sicher und vorteilhaft ist.

Schlüsselwörter

ESPB · Onkologie · ERAS · Rocuronium · Sensorisches Ausmaß

14. Rawal N (2012) Epidural technique for postoperative pain: gold standard no more? Reg Anesth Pain Med 37(3):310-317

15. Hebbard PD (2009) Transversalis fascia plane block, a novel ultrasound-guided abdominal wall nerve block. Can J Anaesth 56(8):618-620

16. Forero M, Adhikary SD, Lopez H, Tsui C, Chin KJ (2016) The erector spinae plane block: a novel analgesic technique in thoracic neuropathic pain. Reg Anesth Pain Med 41(5):621-627

17. Chin KJ, AdhikaryS, Sarwani N, Forero M (2017) The analgesic efficacy of pre-operative bilateral erector spinae plane (ESP) blocks in patients having ventral hernia repair. Anaesthesia 72(4):452-460

18. Elyazed AMM, Mostafa SF, Abdelghany MS, Eid GM (2019) Ultrasound-guided erector spinae plane block in patients undergoing open epigastric hernia repair: a prospective randomized controlled study. Anesth Analg 129(1):235-240

19. Bang S, Chung J, Kwon W, Yoo S, Soh H, Lee SM (2019) Erector spinae plane block for multimodal analgesia after wide midline laparotomy: a case report. Medicine 98(20):e15654

20. Altinpulluk EY, Ozdilek A, Colakoglu $\mathrm{N}$ et al (2019) Bilateral postoperative ultrasound-guided erector spinae plane block in open abdominal hysterectomy: a case series and cadaveric investigation. Rom J Anaesth Intensive Care 26(1):83-88
21. Fang B, WangZ, HuangX(2019) Ultrasound-guided preoperative single-dose erector spinae plane block provides comparable analgesia to thoracic paravertebral block following thoracotomy: a single center randomized controlled doubleblind study. Ann Transl Med 7(8):174

22. Altiparmak B, Korkmaz Toker M, Uysal Al, Gumus Demirbilek S (2019) Comparison of the efficacy of erector spinae plane block performed with different concentrations of bupivacaine on postoperative analgesia after mastectomy surgery: ramdomized, prospective, double blinded trial. BMCAnesthesiol 19(1):31

23. Munoz F, Cubillos J, Bonilla AJ, Chin KJ (2017) Erector spinae plane block for postoperative analgesia in pediatric oncological thoracic surgery. Can JAnaesth 64(8):880-882

24. Piraccini E, Biondi G, Corso RM, Maitan S (2020) The use of rhomboid intercostal block, parasternal block and erector spinae plane block for breast surgery. J Clin Anesth 59:10

25. Fusco P, De Paolis V, De Sanctis F, Di Carlo S, Petrucci E, Marinangeli F (2019) The association of erector spinae plane block and ultrasound guided dry needling could be a winning strategy for long-term relief of chronic musculoskeletal pain. Minerva Anestesiol 85(10):1138-1139

26. Chin KJ, Malhas L, Perlas A (2017) The erector spinae plane block provides visceral abdominal 


\section{Originalien}

analgesia in bariatric surgery: a report of 3 cases. Reg Anesth Pain Med 42(3):372-376

27. Forero M, Rajarathinam M, Adhikary S, Chin KJ (2017) Erector spinae plane (ESP) block in the management of post thoracotomy pain syndrome: a case series. Scand J Pain 17:325-329

28. Tsui BCH, Fonseca A, Munshey F, McFadyen G, Caruso TJ (2019) The erector spinae plane (ESP) block: a pooled review of 242 cases. J Clin Anesth 53:29-34

29. Luis-Navarro JC, Seda-Guzman M, Luis-Moreno C, Chin KJ (2018) Erector spinae plane block in abdominal surgery: case series. Indian J Anaesth 62(7):549-554

30. Petsas D, Pogiatzi V, Galatidis T et al (2018) Erector spinae plane block for postoperative analgesia in laparoscopic cholecystectomy: a case report. JPain Res 11:1983-1990

31. Byrne K, Smith C (2020) Human volunteer study examining the sensory changes of the thorax after an erector spinae plane block. Reg Anesth Pain Med 45(10):761-762. https://doi.org/10.1136/ rapm-2019-101019

32. Yang HM, Choi YJ, Kwon HJ (2018) Comparison of injectate spread and nerve involvement between retrolaminar and erector spinae plane blocks in the thoracic region: a cadaveric study. Anaesthesia 73(10):1244-1250 